\title{
A iluminação cênica no processo criativo da atuação: princípios e práticas na Companhia de Teatro Engenharia Cênica
}

Scenic lighting in the creative process of acting: principles and practices in the Theater Company Engenharia Cênica

Luiz Renato Moura ${ }^{1}$ 


\section{Resumo}

O objeto de estudo deste artigo está centrado na problematização de como a experimentação da iluminação cênica na sala de ensaio colabora com a criação dos atores. A argumentação está fundamentada pelas experiências da Companhia de Teatro Engenharia Cênica, do estado do Ceará, em diálogo com os conceitos de atuação polifônica de Ernani Maletta e visualidade de Eduardo Tudella, com o objetivo de levantar questões a respeito de como as relações entre iluminação e atuação podem ser investigadas na gênese da criação da cena.

Palavras-chaves: lluminação cênica; atuação polifônica; visualidade; processo criativo

\section{Abstract}

The object of study of this article is centered on the problematization of how the experimentation of stage lighting in the rehearsal room collaborates with the creation of the actors. The argumentation is based on the experiences of Theater Company Engenharia Cênica, from the state of Ceará, in dialogue with the concepts of polyphonic acting of Ernani Maletta and visuality of Eduardo Tudella, aiming to raise questions about how the relations between lighting and acting can be investigated in the genesis of scene creation.

Keywords: Stage lighting; polyphonic acting; visuality; creative process

E-ISSN: 2358.6958

\footnotetext{
1 Prof. Dr. Curso de Licenciatura em Teatro - Universidade Regional do Cariri (URCA), Crato - Juazeiro do Norte (CE). Ator, encenador e iluminador cênico. luiz.moura@urca.br
} 
A iluminação cênica é um elemento visual da cena e por isso precisa ser experimentada como uma "instância discursiva" (Maletta, 2016, p. 58) que compõe com a atuação. Neste artigo está o registro de parte da tese de doutorado intitulada "Os elementos visuais do espetáculo no processo criativo do ator"2, cujo foco central foi a investigação de como a iluminação, cenografia, figurino e maquiagem estão presentes na gênese da criação da atuação. De que modo essas instâncias discursivas podem interagir ainda na sala de ensaio? Qual o papel da atuação no processo criativo da iluminação de uma cena?

A Companhia de Teatro Engenharia Cênica ${ }^{3}$ vem, ao longo de quinze anos, construindo uma poética que se pauta na compreensão de que os elementos visuais do espetáculo são criados em consonância com a "atuação" na sala de ensaio (Ferracini, 2013). No que diz respeito ao processo de concepção da iluminação cênica, é considerada a possibilidade do surgimento de um ator-iluminador ${ }^{4}$. Esse, por sua vez, pode definitivamente assumir a concepção da iluminação da encenação, como também àquele que efetivamente a incorpora em sua atuação, compreendendo sua presença na gênese de sua ação.

As principais encenações que se basearam nesse processo de diálogo foram as seguintes: Irremediável, do ano 2007, realizada na cidade de Sobral-CE; Doralinas e Marias, do ano 2009, realizada na cidade de Salvador-BA; O Menino Fotógrafo, do ano 2011, realizada na cidade de Crato-CE; O Evanescente Caminho, do ano 2013, realizada na cidade de Juazeiro do Norte-CE e O Inspetor Geral, do ano 2018, realizada na cidade de Crato-CE.

Em cada um desses processos criativos a Engenharia Cênica foi ampliando princípios que se tornaram procedimentos práticos. E estes, assumidos pela atuação, potencializam a relação entre corpo e visualidade na investigação da cena, quais sejam: o estudo do espaço cênico e das linhas de força na composição da cena; a percepção da transição entre o tempo real e dramático e da cenografia como um envolvimento; a incorporação da iluminação cênica desde o início do processo criativo; o figurino e a maquiagem como determinantes da instalação conceitual do corpo; a improvisação como propulsora dos elementos visuais e de atmosferas; consideração da voz atmosférica como elemento visual ${ }^{5}$.

Em se tratando especificamente da iluminação cênica no processo criativo da atuação, na Companhia de Teatro Engenharia Cênica a luz é compreendida na sala de ensaio como um elemento que, além de definir, revelar e esculpir a cena, é fundamental como instrumento ativo no processo criativo. Quando articulada com a atuação, oferece a possibilidade de expandir a pesquisa dos atores, norteando-os no momento de uma improvisação, ampliando a percepção do espaço cênico e dramá-

\footnotetext{
2 Desenvolvida no Programa de Pós-Graduação em Artes, da Escola de Belas Artes da Universidade Federal de Minas Gerais, com orientação do professor Dr. Ernani de Castro Maletta. Data da defesa: 11/03/2019.

3 Criada em 2005, na cidade de Sobral no Ceará, pela encenadora Cecília Maria e o ator Luiz Renato, com a colaboração dos artistas Jander Alcântara, Daniel Glaydson, Maicon Rocha, e Jult Marques.

4 Conceito estudado em: Luiz Renato Gomes Moura. A iluminação cênica no trabalho do ator de teatro. Natal, 2014. Dissertação (Mestrado) - Programa de Pós-graduação em Artes Cênicas, Universidade Federal do Rio Grande do Norte.

5 Esses princípios, bem como os direcionamentos práticos para experimentá-los, estão detalhados em: Luiz Renato Gomes Moura. Os elementos visuais do espetáculo no processo criativo do ator. Belo Horizonte, 2019. Tese (Doutorado) - Programa de Pós-Graduação em Artes, Universidade Federal de Minas Gerais.
} 
tico por meio da "atmosfera" (Pavis, 2017, p. 37- 38) instaurada pelo corpo em ação.

Os conceitos "atuação polifônica", cunhado por Ernani Maletta (2016, p. 67), e "visualidade", estudado por Eduardo Tudella (2017, p. 42), ampliaram neste artigo a compreensão de que a atuação é uma composição e que, por isso, o ator deve ter interesse em perceber os demais processos criativos que envolvem uma cena, tentando compreendê-los como extensões de suas ações corporais. A sala de ensaio é o lugar onde a ideia é experimentada pela atuação, dessa forma, o envolvimento do ator com a iluminação se estabelece nos momentos iniciais do processo criativo, à medida que ele investiga corporalmente os aspectos visuais presentes na cena.

A partir das encenações da Companhia de Teatro Engenharia Cênica e de uma revisão bibliográfica, foi desenvolvida uma argumentação neste artigo sobre como o processo criativo da atuação articula princípios e práticas que propiciam caminhos para o desenvolvimento de um projeto de iluminação cênica.

\section{A atuação como geradora da cena}

O movimento é para a atuação o ponto inicial do processo de materialização da cena. Na compreensão de Adolphe Appia, em seu livro A Obra de Arte Viva, "o corpo vivo é, assim, o criador dessa arte [...]. É do corpo, plástico e vivo, que devemos partir" (Appia, 2005, p. 13). A atuação, efetivamente, materializa os rascunhos iniciais da cena. Para Constantin Stanislavski (2001, p. 32), "acima de tudo, o teatro existe para o ator, sem o qual não pode existir". Para Antonin Artaud (1995, p. 38), "a encenação propriamente dita, as evoluções dos atores, não deverão ser consideradas senão como os signos visíveis de uma linguagem invisível ou secreta". A pesquisadora Sônia Machado de Azevedo acrescenta a esse pensamento quando considera que o corpo "não será nunca um invólucro, mas a concretude que torna visível e palpável a invisibilidade" (2004, p. 136).

A cena é o resultado do diálogo entre a ideia, a investigação da atuação e a interação com os demais artistas presentes na criação. Os partícipes do processo miram o corpo como um meio pelo qual é possível alcançar caminhos para as pesquisas das diversas "instâncias discursivas" (Maletta, 2016, p. 58) presentes na cena. A iluminação pode ser compreendida como uma instância que constrói dramaturgia na interação com o processo criativo da atuação. O professor e pesquisador brasileiro Eduardo Tudella, em seu livro A Luz na Gênese do Espetáculo (2017, p. 23), considera que a palavra dramaturgia traz na sua etimologia a "acepção construída na raiz grega, cuja origem está em dran [do grego $\delta \rho \alpha ́ \mu \alpha$ - ou agir, ação], de onde teria se originado o termo drama". Portanto, o conceito de dramaturgia está necessariamen-te relacionado, aqui, com a palavra ação. A pesquisadora Sílvia Fernandes acrescenta uma argumentação que corrobora para ampliação da acepção do conceito, quando diz que "o termo não é mais entendido como regra de construção de um texto dramático" (Fernandes, 2013, p. 337).

A atuação é um elemento vivo que une as diversas dramaturgias na cena, por isso que durante o período de ensaios é fundamental a aproximação com o processo de criação dos elementos visuais. Dessa forma, o ator é compreendido como um agente da construção da visualidade, portanto da iluminação, principalmente porque 
principia uma composição entre as instâncias discursivas da cena. Eduardo Tudella compartilha a seguinte argumentação sobre o conceito de visualidade:

[...] ainda que o acionamento da visão, através da adição de luz, torne a cena "visível", tal operação "física" resultará na visualidade do espetáculo, mesmo que essa visualidade não atenda a quaisquer critérios artísticos. A visualidade, [...] está relacionada à postura crítica que orienta o iluminador e confere qualidade estética à sua contribuição para a práxis cênica. (Tudella, 2017, p. 42).

A visualidade é articulada por meio de outros canais na fruição do público e se diferencia da visibilidade exatamente porque considera que a cena é apreciada por todos os sentidos do corpo. Isso provoca a imaginação em quem a frui, como um elemento fundamental para o estabelecimento do diálogo entre atuação e os elementos visuais do espetáculo, ou seja, o espectador passa a ser também compositor da cena.

Portanto, a sala de ensaio é o lugar que propicia a investigação dessa interface entre atuação e iluminação, bem como com todos os demais elementos. Porém, é preciso observar como os atores em processo de criação já são instauradores da visualidade da cena. O pesquisador Jacó Guinsburg apresenta uma argumentação que colabora para esse entendimento e qualifica a função da atuação ao apontar para a ideia de que o ator, por ser um compositor da cena, é também um encenador da ação:

O corpo do comediante investido do papel estabelece por si um espaço cênico, mesmo quando em grau zero cenográfico, isto é, em tablado nu ou num simples lugar qualquer de um desempenho. Este, por outro lado, na proporção em que produz a máscara e concretiza a metamorfose do ator em personagem, incorpora de certa forma, se não a totalidade, no mínimo partes vitais do trabalho do diretor, sendo possível ver, sobretudo no palco dramático, a interpretação do ator como o órgão principal da realização do encenador. (Guinsburg, 2007, p. 09-10).

Sendo o corpo o instaurador do espaço, é nele que se estabelecem os caminhos para a visualidade. A partir dessa observação, o iluminador cênico gera para si (através da sua capacidade de imaginar e influenciado pelo o que o ator propicia com seu processo criativo) estratégias que podem deflagrar o processo de criação da iluminação cênica. O corpo, quando em estado cênico, ou seja, quando está pesquisando a cena, é por excelência uma fonte de intenções e emoções, que transformam o espaço cênico no espaço dramático da cena. Os elementos visuais são principiados pelas imagens que são geradas na criação da cena, se articulam na ação viva da atuação, que redimensiona o espaço cênico e instala um espaço dramático repleto de um discurso invisível. De acordo com Patrice Pavis:

O espaço dramático é construído quando fazemos para nós mesmos uma imagem da estrutura dramática do universo da peça: esta imagem é constituída pelas personagens, pelas ações e pelas relações dessas personagens no desenrolar da ação [...]. Cada espectador, consequentemente, tem sua própria imagem subjetiva do espaço dramático, e não é de se espantar que o encenador só escolha, também ele, uma possibilidade de lugar cênico concreto [...]. O espaço dramático está em perpétuo movimento [...] O espaço dramá- 
tico é o espaço da ficção [...] sua construção depende [...] de nosso esforço de imaginação. Nós o construímos e modelamos a nosso bel prazer, sem que ele nunca se mostre ou se anule numa representação real do espetáculo. Esta é a sua força e também sua fraqueza, pois ele "fala menos ao olho" do que o espaço cênico concreto. Por outro lado, o espaço dramático (simbolizado) e o espaço cênico (visto) misturam-se sem cessar em nossa percepção, um ajudando o outro a construir-se, de modo que, ao cabo de um momento, somos incapazes de discernir o que nos é dado e o que nós mesmos fabricamos. (Pavis, 2008, p. 135-136).

A partir da referida citação, o processo que envolve a criação da atuação na sala de ensaio se fundamenta na relação direta com a visualidade na medida em que investiga, no espaço cênico, a instalação do universo dramático da cena. Nesse sentido, o espectador é levado a fruir a obra por meio das diretrizes que se apresentam no estabelecimento do espaço dramático e, dessa forma, esse último só é possível pela composição entre os elementos visuais do espetáculo em consonância com o movimento vivo da atuação na cena.

Sônia Machado de Azevedo estabelece uma argumentação que corrobora para a ideia do corpo como elemento que compartilha informações e, por isso, é a base para a criação. Em se tratando do ator, "seu corpo adquire um status outro que é o de material a ser experimentado e, sobretudo dominado, de objeto a ser possuído e transformado" (Azevedo, 2004, p. 135). A ideia de que a presença viva é o ponto de partida para a cena também é defendida por Pamela Howard, quando afirma que "o ser humano é o centro vital do teatro, tanto o diretor quanto o cenógrafo só iniciam o trabalho através do ator - o mais importante elemento vivo do espaço6" (Howard, 2009, p. 156).

Nesse processo de materialização da cena, as informações perpassam o processo criativo da atuação e são envolvidas pelas experiências dos atores, compreendidas e expressadas a partir do diálogo que se estabelece entre a concepção e a materialidade. Nesse sentido, Christine Greiner propõe que o corpo não é somente um recipiente, mas sim um lugar de cruzamentos. Em sua opinião, trata-se de um "corpomídia", de um corpo que "não é um meio por onde a informação simplesmente passa, pois toda informação que chega entra em negociação com as que já estão" (Greiner, 2005, p. 130). Em diálogo com a autora, a substancialidade da cena acontece no exato momento em que "o processo imaginativo se desenvolve" (Greiner, 2005, p. 64).

Diante do exposto, é preciso considerar na criação da atuação os princípios para os elementos visuais do espetáculo. As ações constroem caminhos invisíveis para o estabelecimento da visualidade da cena, por isso, é fundamental que iluminadores, cenógrafos, figurinistas, maquiadores e todos os artistas responsáveis pelo design da cena compreendam o corpo do ator como ponto de partida para a criação da visualidade. Pamela Howard, em seu livro "O que é cenografia?", traduzido por Carlos Szlak, apresenta uma argumentação para a compreensão de que os artistas responsáveis pela criação dos elementos visuais do espetáculo devem estabelecer conexões com o pro-

\footnotetext{
${ }^{6}$ Do original: "The human being is at the centre of live theatre, and both the director and the scenographer start working from the actor - the most powerful living element in the space". (Tradução nossa).
} 
cesso criativo da atuação. Destaca-se, nesse sentido, o seguinte trecho do seu livro:

Quando os designers se redefinem como cenógrafos, indicam que estão dispostos a ir além de simplesmente desenhar cenários e figurinos para a criação de um quadro cênico atraente. Significa que estão preparados para observar e estudar os atores no ensaio, compreender como uma atuação se desenvolve e como o ambiente cênico e os figurinos podem trabalhar juntos para melhorar o desempenho do ator. Nem sempre é fácil. Os atores são móveis, imprevisíveis, perigosos e têm um poder de transformação no palco todas as noites. O trabalho do cenógrafo é achar uma maneira de se comunicar com os atores, avaliar suas necessidades e tomar decisões corretas que alcançarão um resultado único e harmonioso. (Howard, 2015, p. 191).

A imaginação é um dispositivo essencial para o processo criativo da cena, principalmente porque é por meio dela que os artistas experimentam a criação que se estabelece na atuação. A imaginação pode ser considerada como a base para o estabelecimento do diálogo entre a ação dos elementos visuais do espetáculo e o processo criativo da atuação. Isso porque nem sempre os artistas podem experimentar seus projetos com antecedência. O compartilhamento das ideias na sala de ensaio influencia objetivamente o processo criativo do ator. Em se tratando da iluminação da cena, por exemplo, o ator, ao dialogar com o iluminador, passa a pesquisar em suas ações as atmosferas resultantes desse diálogo. Ao assumir as diretivas do iluminador, começa sua experimentação tendo como norte uma ideia que articula o processo criativo da dramaturgia da iluminação.

Assim, sem a imaginação e o seu compartilhamento, a visualidade da cena não é possível de ser acessada ainda na sala de ensaio. Quando ela é a gênese do que o ator burila, sua percepção só pode ser estabelecida por meio da capacidade que o artista tem de imaginar aquilo que cria. Nesse sentido, o corpo visível torna-se a ponte para que a visualidade possa se instaurar, assim, em nenhum momento a criação corporal é compreendida como algo estanque, mas como algo que se expande para as ações dos elementos que atuam dramaturgicamente para a instalação da visualidade.

A cena é resultante de um intenso e complexo diálogo entre diversas instâncias discursivas e, por isso, não deve ser compreendida como algo que se sustenta apenas na movimentação física do ator. Segundo Eduardo Tudella (2017, p. 59) a "cena é uma arte compósita", sua prática só é possível por meio do entrelaçamento entre diversos "aspectos constitutivos - desde a dramaturgia, passando pelo ator, pela cenografia, até a luz - se relacionam de modo não linear, transversal" (Tudella, 2017, p. 25). Dessa forma, toda ação presente na performance da atuação é deflagradora de possibilidades atmosféricas, que provocam caminhos para a fruição de sensações, emoções e imagens que invadem o universo particular daquele que observa e reage à cena. Assim, a investigação no teatro se dá por meio da cena, ou seja, as concepções só ganham materialidade quando buriladas pela ação viva do corpo em estado de experimentação, esse processo gera uma pesquisa que propicia caminhos para a criação da iluminação cênica. 


\section{A iluminação cênica no processo criativo da atuação}

Para Roberto Gill Camargo, em um processo criativo de uma encenação teatral "corpo e luz não se dissociam. Ao contrário, formam um processo único, de codependência" (Camargo, 2012, p. 43). A iluminação cênica é uma instância discursiva da cena e deve estar presente em todas as etapas da concepção de uma encenação. Mesmo no momento em que a criação se baseia na construção de uma ideia, ou seja, no momento que antecede ao processo criativo do ator, a iluminação já está presente nas imagens que compõem o imaginário do encenador.

Em muitos espetáculos de teatro a ação da iluminação cênica aparece desconectada da cena, se desenrola por meio de uma narrativa de efeitos que acaba por constituir uma apresentação à parte. Esse problema pode ser muitas vezes decorrente de dois aspectos: da falta de compreensão da importância da iluminação cênica ser articulada na sala de ensaio; ou quando o iluminador não entende que o seu trabalho é fazer significar junto com a encenação um sentido global (Roubine, 1998). Eduardo Tudella acrescenta outras questões que ainda tardam o processo criativo da iluminação cênica na sala de ensaio:

Ainda hoje se tem notícia de espetáculos contemporâneos que estreiam sem um único ensaio para a luz. Em parte, por pressões de natureza econômica que obrigam um diretor e sua equipe a levar à cena um espetáculo por amadurecer. Afinal, pode não ser suficiente ensaiar exaustivamente fora do teatro - ou local onde o evento vai ocorrer - chegando aí apenas num momento tão próximo da estreia que não permite qualquer amadurecimento da visualidade, o que inclui ensaios de luz. (Tudella, 2012, p. 20).

Há ainda um detalhe que reforça a ausência da compreensão da luz como um elemento dramatúrgico a ser estudado na sala de ensaio: a ideia de que a iluminação só pode ser ensaiada em espaços que possuam refletores e estrutura elétrica. Saída alternativa para esse impasse é pensar a iluminação que, antes de tecnologia, é a emoção do ator, a atmosfera que se instala nos ensaios, é a ideia do espaço dramático que se quer alcançar, é a trama, a ação da cenografia, do figurino, da maquiagem, da sonoridade.

Refletindo a iluminação cênica e sua relação com a atuação, a criação do ator é uma base fundamental para a concepção de um projeto de luz para uma cena. Mas como problematizar a iluminação por meio da investigação do ator na sala de ensaio?

Primeiramente é importante o desenvolvimento da compreensão de que é no corpo do ator que o iluminador cênico deve mirar para formular suas ideias iniciais para o projeto de iluminação. Os primeiros diálogos com os atores são necessários porque colaboram com o processo criativo do iluminador, dessa forma, sua criação terá como ponto de partida as cenas que são estabelecidas por meio do corpo e que propiciam desenhos dramatúrgicos para a iluminação cênica. A partir dessa relação processual da criação da iluminação cênica interagindo com o trabalho do ator, vão se organizando métodos e técnicas que reafirmam a iluminação como um processo criativo que surge nas improvisações da cena. 
O iluminador cênico, ao interagir diretamente com o processo de criação da atuação, observa a invisibilidade da luz presente na ação e constrói estratégias para materializar a dramaturgia da iluminação que existe no menor gesto do ator quando cria. A partir desse pensamento, pode-se aferir que é papel do iluminador cênico evitar processos criativos que se desenvolvam distantes da relação com a criação do ator. As reflexões de Parker e Smith (1963) colaboram para essa argumentação:

Todos concordam que a luz é necessária, a fim de que os atores possam ser vistos, que é útil para diferenciar cenas entre a noite e o dia, e que pode, em virtude de alguma magia ou outra, criar um clima. E isso é o máximo que muitas pessoas pensam sobre o assunto. [uma] Boa iluminação (...) deve unir todos os aspectos visuais do palco. Não é suficiente apenas para iluminar atores, marcações, propriedades e figurinos. Partes do cenário podem precisar ser anuladas, certas propriedades podem exigir acentuação, os figurinos bonitos podem ser reforçados. Em resumo, todos os objetos que aparecem no palco devem ser focados pela luz em uma imagem que transmita sentimento e sensação para o público. (Parker; Smith, 1963, p. 244). ${ }^{7}$

De acordo com os referidos autores, para se concretizar como uma instância discursiva na cena, a iluminação cênica é um elemento que precisa estar conectado diretamente à atuação. A relação que pode ser estabelecida entre a iluminação e o processo criativo do ator depende do seu interesse por compreender como a luz pode afetar o seu trabalho, como ela pode definir emoções e colaborar nos seus deslocamentos. A atuação pode se expandir sobremaneira, ao assumir em seu processo de criação diretrizes do iluminador que potencializem os estados emotivos e de energia da cena. Parker e Smith acrescentam ainda que a iluminação está presente no entorno do ator para colaborar com a sua atuação:

Na verdade, este pode ser considerado o mais importante dever da luz no palco: dar ao ator significado em seu entorno, fornecer-lhe o ambiente em que ele pode interpretar com sensibilidade o seu papel, para ajudá-lo em todos os sentidos para trazer ao público o pleno significado e emoção. (Parker; Smith, 1963, p. 244) .

No encontro do iluminador com o corpo do ator na sala de ensaio, a luz se revela como algo inerente para a existência da obra, isso porque na maioria das vezes o espetáculo teatral é criado para ser enxergado como um todo. Mesmo quando a proposta requer a ausência completa da luz, a iluminação já se torna um elemento absolutamente basilar para a efetivação da cena. O iluminador deve criar estratégias de experimentação do seu projeto para que os demais artistas possam se apropriar conceitualmente de suas ideias e experimentá-las, dessa forma abre-se um canal de

\footnotetext{
7 Do original: Everyone agrees that light is needed in order that the actors may be seen, that it is useful to differentiate between night and daytime scenes, and that it can, by virtue of some magic or other, create a mood. And this is as far as many people think on the subject. Good lighting [...] should tie together all the visual aspects of the stage. It is not enough to illuminate players, settings, properties, and costumes. Portions of the scenery may need to be subdued, certain properties may require accenting, handsome costumes must be enhanced. Briefly, all objects that appear on the stage must be focused by light into a picture that conveys sense and feeling to the viewing audience. (Tradução nossa)

8 Do original: In fact, this might be considered the most important duty of light on the stage: to give the actor meaning in his surroundings, to provide him with as environment in which he may sensibility interpret his role, to assist him in every way to bring to the audience the full meaning and emotion. (Tradução nossa)
} 
diálogo que permite perceber as contribuições que o ator, por exemplo, pode oferecer para o projeto de iluminação.

\title{
Atuação polifônica no processo criativo da iluminação cênica
}

O distanciamento entre iluminação e sala de ensaio está mudando. Em diversas montagens atuais é possível notar como as fichas técnicas estão compostas por artistas que exercem mais de uma função no processo criativo, ou seja, que se propõem a conceber outras dramaturgias. Atores-iluminadores, cenógrafos-figurinistas, encenadores-dramaturgos e tantas outras possibilidades. Essa atuação polifônica (Maletta, 2016) tem proporcionado uma abordagem ampla das instâncias discursivas da cena pelo simples fato de que um ator, ao ser também iluminador, não separa os dois processos, pelo contrário, problematiza-os, e faz com que a atuação e a iluminação cênica sejam constantemente articuladas na sala de ensaio. Esse movimento de ressignificação do espaço de criação da cena colabora para a noção de que a sala de ensaio é um espaço pedagógico no qual são compartilhadas habilidades e competências, o que promove uma ampla formação dos partícipes da criação.

Para que a iluminação cênica esteja presente no processo criativo do ator, é necessário que ele desempenhe uma atuação polifônica. O professor Ernani Maletta apresenta, em livro publicado em 2016 e intitulado "Atuação polifônica: princípios e práticas", uma importante estratégia para o ator compreender a dimensão do seu processo criativo quando está diretamente relacionado com a iluminação cênica. Para Maletta, trata-se de um ator multiperceptivo, exatamente aquele "que conseguiu perceber, compreender, incorporar e se apropriar dos conceitos fundamentais que definem e sustentam cada forma de expressão artística" (Maletta, 2016, p. 24). De acordo com suas palavras, quando o ator compreende a natureza polifônica de sua atuação, os caminhos para o estabelecimento do diálogo com os elementos visuais se concretizam por meio de uma incorporação dos discursos:

\begin{abstract}
Fundamentando-me então, como premissa, na natureza polifônica do Teatro, afirmo que cada artista teatral, que é certamente uma das vozes da partitura teatral, deveria apropriar-se das diversas outras vozes responsáveis pelos vários discursos que acontecem simultaneamente no ato teatral: as vozes dos atores, do autor, do diretor/encenador, do dramaturgo, do diretor musical/ sonoplasta, dos preparadores vocal e corporal, do cenógrafo, do figurinista, do iluminador, do caracterizador e de todos os demais criadores do espetáculo. Assim, ao incorporar vários outros discursos ao seu próprio discurso, apropriando-se deles, o artista cria para si um discurso polifônico. É oportuno ressaltar que a existência de todas essas vozes, relacionada às diversas funções da criação cênica, não necessariamente implica a presença de um artista cênico diferente para cada uma delas. Um mesmo artista pode se responsabilizar por várias funções e, com isso, gerar múltiplos pontos de vista diversos. (Maletta, 2016, p. 67).
\end{abstract}

Diante do exposto, o ator em processo criativo pode desenvolver uma atuação polifônica, e por meio dela é possível o diálogo com a iluminação cênica ainda na sala de ensaio. Não é necessário que os refletores estejam presentes no ensaio para que 
a iluminação cênica componha o processo criativo da atuação, pois antes mesmo da definição dos equipamentos que serão utilizados, a luz é sensação, atmosfera, é efetivamente parte do universo simbólico que se instaura na construção da personagem, do espaço dramático da cena. Dessa forma, o ator pode compreender que “[...] quando falamos em iluminação cênica, estamos pensando não só em tornar visível, mas em construir uma visibilidade determinada. Não se trata apenas de ver, mas como ver" (Simões, 2008, p. 18).

Com base no pensamento de Maletta, esse ator que atua polifonicamente, considera a ação da iluminação cênica no seu processo criativo, envolve-se com a dramaturgia da luz, assumindo-a com suas ações cênicas, "apropriando-se dos múltiplos discursos propostos pelos demais criadores" (Maletta, 2016, p. 67). Há uma ampliação sinestésica do corpo do ator quando este compreende as atmosferas da luz como extensões de sua ação. Nessa perspectiva, a iluminação torna-se um elemento que compõe a atuação.

A iluminação cênica, quando assumida pela atuação ainda nos momentos iniciais do processo criativo, possibilita uma percepção expandida na construção da cena, abrindo os percursos para o entendimento das atmosferas, bem como das intenções que se almejam garantir com a visualidade. A iluminação está completamente conectada à criação da atuação, ela torna visivel a expressão dos atores. O ator que compreende a luz cênica como um instrumento que fortalece o que ele expressa, passa a entender que a composição é uma atividade que fundamenta a criação teatral e que, por isso, deve ser assimilada nos detalhes do processo criativo. Isso faz com que o ator não se limite ao entendimento de que a cena depende exclusivamente do seu desempenho, e sim que sua função é exatamente ser o filtro que conecta as dramaturgias presentes na cena.

Através desse caminho, o ator poderá acompanhar as diversas etapas de concepção de um projeto de iluminação, o que, consequentemente, facilitará o seu trabalho quando as propostas forem efetivamente executadas com os equipamentos. Se na sala de ensaio o ator desenvolveu a consciência sobre os movimentos da iluminação e os seus possíveis desenhos, como focos, corredores, cores e etc., na ocasião em que ele tiver contato com os refletores, nenhuma dessas informações será nova ou inesperada, mas sim, farão parte de um projeto que foi experimentado.

\section{Referências}

APPIA, Adolphe. A Obra de Arte Viva. 3. ed. Amadora-PT: ESTC, 2005.

ARTAUD, Antonin. Linguagem e vida. São Paulo: Perspectiva, 1995.

AZEVEDO, Sônia Machado. O papel do corpo no corpo do ator. São Paulo: Perspectiva, 2004.

CAMARGO, Roberto Gill. Conceito de iluminação cênica: processos coevolutivos. Rio de Janeiro: Música e Tecnologia, 2012. 
FERNANDES, Sílvia. A encenação. In: FARIA, João Roberto (dir.). História do Teatro Brasileiro, volume 2: do modernismo às tendências contemporâneas. São Paulo: Perspectiva Edições SESC, 2013.

FERRACINE, Renato. Ensaios de atuação. São Paulo: Perspectiva, 2013.

SIMÕES, Cibele Forjaz. À luz da linguagem: a iluminação cênica: de instrumento de visibilidade à 'scriptura do visível' (primeiro recorte: do fogo à Revolução Teatral). São Paulo, 2008. Dissertação (Mestrado em Artes) - Escola de Comunicação e Artes, Universidade de São Paulo, 2008.

GUINSBURG, Jacó. Da cena em cena: ensaios de teatro. São Paulo: Perspectiva, 2007.

MALETTA, Ernani. Atuação Polifônica: princípios e práticas. Belo Horizonte, MG: Editora UFMG, 2016.

MOURA, Luiz Renato Gomes. Os elementos visuais do espetáculo no processo criativo do ator. Belo Horizonte, 2019. Tese (Doutorado) - Programa de Pós-Graduação em Artes, Universidade Federal de Minas Gerais.

MOURA, Luiz Renato Gomes. A iluminação cênica no trabalho do ator de teatro. Natal, 2014. Dissertação (Mestrado) - Programa de Pós-graduação em Artes Cênicas, Universidade Federal do Rio Grande do Norte.

PAVIS, Patrice. Dicionário da performance e do teatro contemporâneo. Tradução de J. Guinsburg. São Paulo: Perspectiva, 2017.

PAVIS, Patrice. Dicionário de teatro. São Paulo: Ed. Perspectiva, 2008.

PARKER, Oren W.; SMITH, Harvey K. Scene design and stage lighting. New York: Holt, Rinehart and Winston, 1963.

HOWARD, Pamela. What is scenography? 2. ed., New York: Routledege, 2009.

HOWARD, Pamela. O que é cenografia? (Trad. Carlos Szlak). São Paulo: Edições SESC São Paulo, 2015.

GREINER, Christine. O corpo: pistas para estudos indisciplinares. São Paulo: Annablume, 2005.

ROUBINE, Jean-Jacques. A linguagem da encenação teatral. Rio de janeiro: Ed. Jorge Zahar, 1998.

STANISLAVSKI, Constantin. Manual do ator. São Paulo: Martins Fontes, 2001. 
TUDELLA, Eduardo. Design, Cena e Luz: anotações. Revista Alberto, São Paulo no 3, p. 11, 2012.

TUDELLA, Eduardo Augusto da Silva. A luz na gênese do espetáculo. Salvador: EDUFBA, 2017.

Recebido em: 30/10/2019

Aprovado em: 05/02/2020

\section{Acréscimo de dados:}

Na versão publicada deste artigo ficou faltando a ficha técnica dos espetáculos citados na página 171. Aqui fazemos a devida correção.

Irremediável - Ficha técnica: Cecília Maria (encenação e dramaturgia), Luiz Renato (atuação e iluminação cênica), Jander Alcântara (atuação), Daniel Glaydson (sonoplastia), Maicon Rocha (operação de iluminação), Jult Marques (contraregra).

Doralinas e Marias - Ficha técnica: Cecília Maria (encenação e dramaturgia), Meran Vargens (atuação), Adriana Amorim (atuação), Daniele França (atuação), Luiz Renato (atuação e iluminação cênica), Zuarte Júnior (cenografia), Rino Carvalho (figurino), Marie Thauront (maquiagem), Luciano Salvador Bahia (direção musical).

O Menino Fotógrafo - A encenação foi realizada com o Grupo Ninho de Teatro. Ficha técnica: Cecília Maria (encenação e dramaturgia), Alana Morais (atuação), Edceu Barboza (atuação, sonoplastia, figurino e maquiagem), Elizieldon Dantas (atuação), Joaquina Carlos (atuação), Luiz Renato (atuação e iluminação cênica), Rita Cidade (atuação) e Zizi Telécio (atuação).

O Evanescente Caminho - Ficha técnica: Cecília Maria (encenação e dramaturgia), Amanda Oliveira (atuação), Lorenna Gonçalves (atuação), Lucivania Lima (atuação), Luiz Renato (atuação e iluminação cênica), Nilso Matos (atuação), Raimundo Lopes (atuação), Emanoel Siebra (sonoplastia), Danilo Brito (iluminação cênica), Carla Hemanuela (figurino e maquiagem).

O Inspetor Geral - Ficha técnica: Cecília Maria (encenação), Nikolai Gógol (dramaturgo), Áleff Alves (atuação), Luiz Renato (atuação e iluminação cênica), Renato Érikles (atuação), Wagner Petrolli (atuação), Edceu Barboza (figurino, maquiagem e projeto gráfico). 